American Journal of Biochemistry and Biotechnology 6 (1): 32-34, 2010

ISSN 1553-3468

(C) 2010 Science Publications

\title{
Secondary Metabolites in Essential Oil of Achillea millefolium (L.) Growing Wild in East Part of Kosova
}

\author{
${ }^{1}$ Arben I. Haziri, ${ }^{1}$ Nevzat Aliaga, ${ }^{2}$ Murtezan Ismaili, ${ }^{1}$ Sevdije Govori-Odai, \\ ${ }^{1}$ Osman Leci, ${ }^{3}$ Fatmir Faiku, ${ }^{4}$ Valentina Arapi and ${ }^{5}$ Imer Haziri \\ ${ }^{1}$ Section of Organic and Biochemistry, Department of Chemistry, \\ Faculty of Natural Science, University of Pristina, "Mother Teresa" Street 5, 10000 Prishtine, Kosova \\ ${ }^{2}$ Department of Environment and Health, South East European University Tetovo, \\ Ilidenska bb, 1200 Tetovo, Macedonia \\ ${ }^{3}$ Section of Analytical and Environmental Chemistry, Department of Chemistry, \\ Faculty of Natural Science, University of Prishtina, "Mother Teresa" Street 5, 10000 Prishtine, Kosova \\ ${ }^{4}$ Department of Chemistry, Faculty of Biotechnology, Agricultural University of Tirana, \\ "Koder Kamez" Street 18, 1007 Tirana, Albania \\ ${ }^{5}$ Section of Biochemistry, Department of Veterinary, Agricultural Faculty, \\ University of Pristina, "Mother Teresa" Street 5, 10000 Prishtine, Kosova
}

\begin{abstract}
Problem statement: Chemical composition of essential oil of Achillea millefolium (L.), originated from east part of Kosova, was investigated. Approach: The chemical profile of the essential oil was evaluated by GC and GC-MS. Results: Analysis of the oil resulted in the identification of 33 peaks, representing $81.4 \%$ of the oil. The main compounds of Achillea millefolium (L.) from east region of Kosova, were 1,8-cineole (22\%), camphor $(21 \%)$, borneol $(7,6 \%)$ and $\beta$-pinene $(5.3 \%)$. Conclusion: After comparison of our date with those reported in literature we can conclude that various chemotypes of Achillea millefolium (L.) occur in nature.
\end{abstract}

Key words: Achillea millefolium (L.), essential oil, east part of Kosova, 1,8-cineole, camphor, borneol, $\beta$-pinene

\section{INTRODUCTION}

Achillea millefolim (L.) is generally known as Yarrow (Benedek et al., 2008). The herb is very common during May and June and it grows in all parts of Kosova. A. millefolium (L.) is used in folk and official medicine (Benedek et al., 2008). It has traditionally used against skin inflammations, hepato-biliary disorder and gastrointestinal complaints. A. millefolium (L.) has been used internally as herbal tea and externally in lotions and herbal medications (Benedek et al., 2008; Smelcorevic et al., 2010; Baser et al., 2002).

The essential oil of A. millefolium (L.) is reported to posses disinfectant properties and has also been used as a haemostatic (Benedek et al., 2008; Smelcorevic et al., 2010; Baser et al., 2002). The chemical profiles of $A$. millefolium (L.) oil have been the subject of number publications over the years (Smelcorevic et al., 2010; Suleimenov et al., 2001; Hofmann et al., 1992). However, to our knowledge no detailed GC-MS analysis of A. millefolim (L.) essential oil from Kosova has been done out so far.

The aim of this study was to investigate the chemical profile of A. milefolium (L.) essential oil, from East part of Kosova and the results are compared to those reported in literature.

\section{MATERIALS AND METHODS}

The aerial part of $A$. millefolium (L.), growing wild in east part of Kosova, was collected in May 2008. Voucher specimens were deposited in the herbarium of the Department of Veterinary, University of Prishtina.

The plants were dried at room temperature. The essential oil of A. millefolium (L.) was extracted with steam distillation for $3 \mathrm{~h}$ of $100 \mathrm{~g}$ of air dried plants. The yield was $0.21 \%(\mathrm{v} / \mathrm{w})$.

The analysis of essential oil was carried out by GC and GC-MS. The HP 5890 II chromatograph equipped with an FID detector and using fused silica capillary

Corresponding Author: Arben I. Haziri, Section of Organic and Biochemistry, Department of Chemistry, FNS, University of Pristina, "Mother Teresa" Street 5, 10000 Prishtine, Kosova 
column (30 $\mathrm{m} \times 0.32 \mathrm{~mm})$, coated with polydimethyl siloxane, was used for quantitative analysis. The GC oven temperature was set at $50^{\circ} \mathrm{C}$ for $3 \mathrm{~min}$, then programmed to $220^{\circ} \mathrm{C}$ at a rate of $5^{\circ} \mathrm{C} \mathrm{min}^{-1}$ and then held isothermal at $220^{\circ} \mathrm{C}$ for $13 \mathrm{~min}$. Nitrogen was the carrier gas. About $1 \mu \mathrm{L}$ of diluted sample was injected manually. The percentage composition of the essential oil was computed from GC peak areas without correction factors.

Analysis by GC-MS was performed using a chromatograph HP 5890 II GC interfaced to a HP 5972 mass spectrometer (ionization voltage $70 \mathrm{eV}$ ) and equipped with capillary column HP-5MS $(50 \mathrm{~m} \times 0.25 \mathrm{~mm})$. The oven temperature was held at $100^{\circ} \mathrm{C}$ for $5 \mathrm{~min}$ and then programmed from $100-250^{\circ} \mathrm{C}$ at a rate of $5^{\circ} \mathrm{C} \mathrm{min}^{-1}$. He was as the carrier gas $\left(1.0 \mathrm{~mL} \mathrm{~min}^{-1}\right)$.

Qualitative analysis was based on a comparison of retention times and indexes on both columns and mass spectra with corresponding data in the literature (Adams, 2001) and computer mass spectra libraries (Wiley and NBS $75 \mathrm{~K}$ ).

\section{RESULTS}

Water-distilled essential oil from aerial part of A. millefolium (L.) was analysed by GC-MS. The identified compounds and their percentage are given in Table 1. The yield was $0.21 \%(\mathrm{v} / \mathrm{w})$. Analysis of the oil resulted in the identification of 33 peaks, representing $81.4 \%$ of the oil. The main compounds of A. millefolium (L.) from east region of Kosova, were 1,8 -cineole (22\%), camphor (21\%), borneol $(7,6 \%)$ and $\beta$-pinene (5.3\%).

\section{DISCUSSION}

The essential oil from aerial parts of A. millefolium (L.), obtained by hidro-distillation was analyzed by GC and GC-MS. The oil yield was $0.21 \%(\mathrm{v} / \mathrm{w})$. When we compare this oil yield with those reported by other authors (Smelcorevic et al., 2010; Baser et al., 2002; Suleimenov et al., 2001; Hofmann et al., 1992), it was seen that we have obtained a very good yield.

Analysis of the oil resulted in the identification of 33 peaks, representing $81.4 \%$ of the oil. The main compounds of A. millefolium (L.) from east region of Kosova, were 1,8-cineole (22\%), camphor (21\%), borneol $(7,6 \%)$ and $\beta$-pinene $(5.3 \%)$.

1,8-Cineol (22\%) and camphor (21\%) in A. millefolium (L.) essential oil from Kosova is in higher quantity than in A. millefolium (L.) oil from Germany (Hofmann et al., 1992), but our oil is in agreement with essential oil of A. millefolium (L.) from Serbia (Smelcorevic et al., 2010) in the percentage composition of 1,8-cineol. Also, essential oil from Kosova contains more camphor than essential oil of A. millefolium (L.) from Serbia (11\%) (Smelcorevic et al., 2010).

Borneol (7.6\%) in A. millefolium (L.) oil from Kosova is in same quantity as in essential oil from Germany (8.1\%) (Hofmann et al., 1992). $\beta$-Pinene (5.3\%) from Kosova's A. millefolium (L.) essential oil, is in lower amount than in oil from Germany (11.5\%) (Hofmann et al., 1992) but our oil matches to a great extent with essential oil from Serbia (Smelcorevic et al., 2010 ) in the percentage of $\beta$-pinene (5.4\%).

The amounts of chemical components in A. millefolium (L.) essential oil from Kosova region are not in agreement with A. millefolium (L.) essential oil from other region. From here we can see the variation on the chemical composition of essential oil of A. millefolium (L.) Also, we have confirmed the conclusion of Hofmann et al. (1992) that various chemotypes of A. millefolium (L.) occur in nature.

Table 1: Chemical composition of Achillea millefolium (L.) essential oil

\begin{tabular}{lcc}
\hline Components & RI & Percent \\
\hline (Z)-3-hexanol & 845 & 0.2 \\
$\alpha$-thyjene & 924 & 0.2 \\
$\alpha$-pinene & 937 & 1.3 \\
camphene & 949 & 0.6 \\
sabinene & 969 & 1.2 \\
$\beta$-pinene & 976 & 5.3 \\
p-cymene & 1015 & 1.6 \\
1,8-cineol & 1026 & 22.0 \\
$\gamma$-terpinene & 1050 & 0.9 \\
trans-sabinene & 1054 & 0.2 \\
cis-sabinene & 1090 & 0.7 \\
$\alpha$-thujone & 1103 & 0.6 \\
camphor & 1127 & 21.0 \\
menthone & 1142 & 1.4 \\
borneol & 1157 & 7.6 \\
terpinen-4-ol & 1166 & 2.9 \\
$\alpha$-terpineol & 1177 & 2.8 \\
myrtenol & 1184 & 1.2 \\
trans-carveol & 1202 & 0.1 \\
bornyl acetate & 1273 & 0.1 \\
cis-jasmone & 1379 & 0.2 \\
$\beta$-caryophyllene & 1417 & 2.6 \\
cis- $\beta$-farnesene & 1450 & 0.1 \\
germacrene D & 1479 & 1.9 \\
$\alpha$-murolene & 1498 & 0.1 \\
$\gamma$-cadinene & 1527 & 0.1 \\
$\alpha$-cadinene & 1536 & 0.1 \\
$\beta$-caryophyllene oxide & 1571 & 3.2 \\
$\beta$-eudesmol & 1638 & 0.2 \\
$\alpha$-eudesmol & 1641 & 0.1 \\
n-octadecane & 1805 & 0.5 \\
n-nonadecene & 1906 & 0.3 \\
(E, E)-fernasyl acetone & 1921 & \\
Total & & \\
\hline RI Ren & & \\
\hline
\end{tabular}

RI: Retention Indices 


\section{CONCLUSION}

The present study presents the chemical profile of the essential oil of Achillea millefolium (L.) from east part of Kosova. 1,8-cineole (22\%), camphor (21\%), borneol $(7,6 \%)$ and $\beta$-pinene $(5.3 \%)$ were the major components. Comparing our results with A. millefolium (L.) oils from different parts of the Europe, it was evident that our oil is different from the others regions on chemical profiles.

After comparison of our date with those reported in literature (Baser et al., 2002; Suleimenov et al., 2001; Hofmann et al., 1992; Smelcorevic et al., 2010), we can conclude that genetic and environmental factors play role in chemical profiles of essential oil of Achillea millefolium (L.).

\section{ACNOWLEDGMENT}

The researchers acknowledge the financial support received from the University of Prishtina, Kosova and from South East European University of Tetovo, Macedonia.

\section{REFERENCES}

Adams, R.P., 2001. Identification of Essential Oil Components by Gas Chromatography/Quadrupole Mass Spectroscopy. 3rd Edn., Allured Publishing, Carol Stream, IL., ISBN: 0-931710-85-5, pp: 456.
Baser, K., B. Demirci, F. Demirci, S. Kocak and C. Akinci et al., 2002. Composition an antimicrobial activity of the essential oil of Acillea multifida. Plant Med., 68: 941-943.

Benedek, B., K.W. Rothwangl, E. Rozema, N. Gjoncaj and G. Reznicek et al., 2008. Yarrow (Achillea millefolium L.s.I.) Pharmaceutical quality of comercial samples. Pharmazi, 63: 23-26. DOI: 10.1691/ph.2008.7646

Hofmann, L., D. Fritz, S. Nitz, H. Kollmansberger and F. Drawert, 1992. Essnetial oil composition of three polyploids in the Achillea millefolium "complex". Phytochemistry, 31: 537-542. DOI: 10.1016/0031-9422(92)90034-N

Smelcorevic, A., M. Lamshoeft, N. Radulovic, D. Ilic and R. Palic, 2010. LCMS analysis of the essential oils of Achillea millefolium and Achillea crithmifolia. Chromatographia, 71: 113-116. DOI: 10.1365/s10337-009-1393-4

Suleimenov, M.Y., A.G. Atazhanova, T. Ozek, B. Demirci and T.A. Kulyyasov et al., 2001. Essential oil composition of three species of Acillea from Kazakhstan. Chem. Nat. Comp., 37: 447-450. DOI: 10.1023/A:1014471326724 